\title{
Concepts for Prehospital and Initial In-hospital Therapy of Status Epilepticus
}

\section{(ㄷ) (2) (1)}

\section{Authors}

Adam Strzelczyk 1, 2, Lara Kay', Christoph Kellinghaus³, Susanne Knake², Anemone von Blomberg', Laurent M. Willems ${ }^{1}$, Felix Rosenow ${ }^{1,2}$

\author{
Affiliations \\ 1 Epilepsy Center Frankfurt Rhine-Main, Center of \\ Neurology and Neurosurgery, Goethe University, \\ Frankfurt am Main, Germany \\ 2 Epilepsy Center Hessen, Department of Neurology, \\ Philipps University, Marburg (Lahn), Germany \\ 3 Epilepsy Center Münster-Osnabrück, Department of \\ Neurology, Klinikum Osnabrück GmbH, Osnabrück, \\ Germany
}

Bibliography

DOI https://doi.org/10.1055/s-0043-110486

Neurology International Open 2017; 1: E217-E223

(c) Georg Thieme Verlag KG Stuttgart · New York

ISSN 2511-1795

\author{
Correspondence \\ Prof. Dr. med. Adam Strzelczyk, MHBA \\ Epilepsiezentrum Frankfurt Rhein-Main \\ Zentrum der Neurologie und Neurochirurgie \\ J.W. Goethe-Universität Frankfurt \\ Schleusenweg 2-16, Haus 95 \\ 60528 Frankfurt am Main \\ Germany \\ strzelczyk@med.uni-frankfurt.de
}

\section{Introduction}

Status epilepticus (SE) is a major neurological emergency associated with significant lethality and morbidity. SE incidence increases with age; thus, with the demographic shift of an aging population, rises in incidence rates are likely. In Germany, at least 16000 to 20000 cases of SE are to be expected annually; the resulting costs of acute in-patient SE treatment amount to over EUR 200 million per year. Mean SE mortality is between 15 and 20\% [1-4].

To treat SE, a large number of anticonvulsants are available which are used in very different therapeutic sequences and in various dosage forms. Whenever possible, SE should be treated in a neurocritical care unit; however, initial treatment should not be delayed by patient transport times to such a unit. Especially in patients with nonconvulsive SE or focal SE who may present with minimal neurological signs and symptoms, an EEG investigation in a clinical neurophysiology department is required to establish the diagnosis. In the prehospital environment, initial treatment needs to be modified to reflect the limited monitoring capabilities available in this setting. This review discusses the options available for prehospital and initial in-hospital treatment of SE (corresponding to stage 1 and stage 2; see below) in non-ICU settings with limited monitoring ca- pabilities, taking into account the most recent SE definition of the International League Against Epilepsy (ILAE) published in 2015 [5] and the current consensus-based (S2k) Guideline on the Management of SE in Adults, issued by the German Neurological Society (Deutsche Gesellschaft für Neurologie, DGN) in 2012 [6].

\section{Definition}

According to the DGN guideline on SE [6], seizures of more than 5 min duration or a series of discrete seizures between which there is incomplete recovery of the previous neurological status is defined as SE and should be treated as soon as possible with sufficiently high doses. The 5-minute time limit dates back to an operational definition proposed by Lowenstein in 1999, aimed at ensuring that patients receive treatment as soon as possible, and which considers any seizure lasting for more than $5 \mathrm{~min}$ as SE [7]. The current ILAE definition sets two time points ( $t 1, t 2)$; while $t 1$ defines the transition of a seizure to SE ( $t 1$ ), depending on semiology, $t 2$ marks the point in time when neurological injury is likely to occur. Regarding the start of SE treatment ( $\mathrm{t} 1$ ), the time limit is $5 \mathrm{~min}$ for generalized convulsive (tonic-clonic) status epilepticus (GCSE), $10 \mathrm{~min}$ 
for complex focal status epilepticus (focal SE with impaired consciousness) and 10 to 15 min for absence status epilepticus [5]. SE-induced neuronal damage is assumed to occur after a time (t2) of 30 min with GCSE and after 60 min with complex focal status epilepticus [5]. Thus, the urgency with which to start treatment is also dependent on the type of SE and appears to be most pressing with GCSE. Clinical and experimental data show a correlation between delayed start of treatment and reduced likelihood of successful SE termination with the first treatment attempt [8-10].

\section{Stage-adapted Therapeutic Principles}

Clinically, four phases of SE are differentiated [11] which are closely associated with the staged approach to treatment described in the following. The time spans listed below apply to a GCSE:

1. Initial phase of SE: A seizure of 5-10 min duration or continuous seizure activity in EEG. There is still a clinically relevant chance of spontaneous termination. Initial treatment with a benzodiazepine is appropriate.

2. Established status epilepticus: Seizure/epileptic activity in EEG of at least 10-30 (maximum 60) minutes or series of seizures between which there is incomplete recovery of consciousness. In addition to the initial treatment with a benzodiazepine, a conventional anticonvulsant is administered intravenously.

3. Refractory status epilepticus: SE persisting after failure of the first and second treatment, usually 30-60 min after start of seizure activity; escalation of therapy is critical. At this point in time, general anesthesia with endotracheal intubation should be administered to patients with GCSE. In patients with focal $\mathrm{SE}$, there is not the same urgency to initiate aggressive anticonvulsive therapy as with GCSE; thus, further stage 2 treatment options should be used.

4. Super-refractory status epilepticus: Super-refractory SE is assumed when general anesthesia was ineffective [11,12]. In this situation, several treatment options are available, including steroids, hypothermia, immunoglobulins, inhalation anaesthetics, ketogenic diet, perampanel, stiripentol, among others; however, all of these treatments lack evidence base and some are associated with limited anticonvulsive efficacy [11,13-15]. Currently, a randomized, double-blind, placebo-controlled study (NCT02477618) on the use of allopregnanolone in patients with super-refractory SE is being performed [16]. Allopregnanolone is a neurosteroid, acting as a positive allosteric modulator of synaptic and extrasynaptic $\mathrm{GABA}_{\mathrm{A}}$ receptors [17].

\section{Initial Phase of Treatment (Stage 1)}

Strong evidence from both clinical $[8,10]$ and animal model data [9] emphasizes the critical role of early initiation of treatment in patients with SE, as therapeutic response to most anticonvulsants deteriorates over the course of SE due to progressive decline in GABAergic inhibition [18]. Consequently, anticonvulsant treatment should be started as early as possible, ideally already before arrival at a hospital [10]:

In the initial phase, benzodiazepines are the drug of choice. With its longer intracerebral half-life and the resulting lower risk of seizure recurrence, lorazepam (LZP) is a clinically suitable drug and evidence-based initial treatment for patients with SE; it may be ad- ministered by paramedics (up to $4 \mathrm{mg}$ ) and emergency physicians, or in a hospital setting (up to $0.1 \mathrm{mg} / \mathrm{kg}$ body weight [BW] intravenously) $[10,19]$. As an alternative to LZP, clonazepam (CLP), another long-acting benzodiazepine, is often used because of its similar pharmacokinetic characteristics [20]; CLP should be slowly administered intravenously as a bolus dose of $0.015 \mathrm{mg} / \mathrm{kg}$ BW. However, data from randomized controlled trials are not available for CLP. A cohort study conducted in Lausanne (Switzerland) and Boston (USA) showed that LZP was more frequently underdosed in everyday clinical practice compared with CLP and associated with a higher risk of a more refractory treatment course [21]. Alternatively, other benzodiazepines can be used (for details on individual benzodiazepines refer to $>$ Table 1). When diazepam (DZP) or midazolam (MDZ) are used, concomitant rapid loading with another anticonvulsant (stage 2) is advisable to compensate for their shorter intracerebral half-life and to reduce the risk of seizure recurrence.

The RAMPART (Rapid Anticonvulsant Medication Prior to Arrival Trial) study compared the efficacy of intramuscular administration of MDZ (total dose of $10 \mathrm{mg}$, administered using an applicator; $5 \mathrm{mg}$ for patients with body weights from $13 \mathrm{~kg}$ to $40 \mathrm{~kg}$ ) with that of intravenous administration of LZP ( $4 \mathrm{mg}$ total dose, $2 \mathrm{mg}$ for patients with body weights from $13 \mathrm{~kg}$ to $40 \mathrm{~kg}$ ) in the prehospital treatment of SE [22-24]. Intramuscular MDZ was superior to intravenous LZP with regard to the rate of GCSE controlled at the time of admission to hospital. This was primarily due to the shorter time to initial administration and emphasizes the need for rapid administration of benzodiazepines in the treatment of SE [25]. Although the time from drug administration to termination of SE was shorter in the arm treated with intravenous LZP, this did not result in statistical superiority because of the longer time needed to establish a secure intravenous access [22-24].

For initial treatment, especially by nursing staff and family members, additional routes of administration with rapid absorption are available, such as the buccal or intranasal administration of MDZ and the rectal administration of DZP. These routes of administration have been extensively studied, especially in children and adolescents, but are often expensive in daily use. Sublingual administration of LZP orally disintegrating tablets and oral administration of CLP or DZP drops should be avoided in the treatment of SE, as a long absorption half-life of about 20 min can occur.

Several studies showed the equivalence or superiority of intranasal or buccal administration of midazolam $(0.2 \mathrm{mg} / \mathrm{kg})$ or lorazepam $(0.05 \mathrm{mg} / \mathrm{kg}$ to a maximum of $4 \mathrm{mg})$ compared with intravenous or rectal administration [26-37]. Thus, intranasal or buccal administration of midazolam (5-10 mg, repeated, if necessary, maximum dose approx. $20 \mathrm{mg}$ ), intramuscular administration of midazolam (10 mg i.m.) or rectal administration of diazepam (10$20 \mathrm{mg}$ rectally, repeated, if necessary, maximum dose approx. $30 \mathrm{mg}$ ) are recommended for the initial treatment of SE in adults.

Among the branded medications, Buccolam is available for buccal administration; however, this product is only approved for the treatment of prolonged, acute, convulsive seizures in infants, toddlers, children and adolescents (from 3 months to $<18$ years). The missing approval of the product for the treatment of adults is due to the streamlined form of the approval process for pediatric use (PUMA, pediatric-use marketing authorization); however, prescribing this medication to adults in an outpatient setting may mean that 
- Table 1 Summary of benzodiazepines for acute treatment of prolonged seizures and status epilepticus.

\begin{tabular}{|c|c|c|c|c|}
\hline & Midazolam & Lorazepam & Clonazepam & Diazepam \\
\hline Typical initial dose in adults" & 5 to $10 \mathrm{mg}$, in $2-3 \mathrm{mg}$ steps & 2 to $4 \mathrm{mg}^{\#}$ & $1 \mathrm{mg}$ & $10 \mathrm{mg}^{\#}$ \\
\hline Recommended intravenous dosage & $0.1 \mathrm{mg} / \mathrm{kg} \mathrm{BW}$ & 0.05 bis $0.1 \mathrm{mg} / \mathrm{kg}$ BW & $0.015 \mathrm{mg} / \mathrm{kg} \mathrm{BW}$ & $0.15 \mathrm{mg} / \mathrm{kg} \mathrm{BW}$ \\
\hline Maximum dosage & $20 \mathrm{mg}$ & $8 \mathrm{mg}$ & $3 \mathrm{mg}$ & $30 \mathrm{mg}$ \\
\hline Routes of administration & $\begin{array}{l}\text { intravenous, intranasal } \\
\text { buccal, intramuscular }\end{array}$ & intravenous & intravenous & intravenous, rectal \\
\hline Half-life & $3-4 h$ & $12-16 h$ & $30-40 \mathrm{~h}$ & $20-100 h^{*}$ \\
\hline Interactions & few & few & many & many \\
\hline Tissue toxicity & low & low & low & low \\
\hline \multicolumn{5}{|l|}{ BW: body weight } \\
\hline \multicolumn{5}{|c|}{${ }^{*}$ short duration of action in CNS due to rapid redistribution } \\
\hline
\end{tabular}

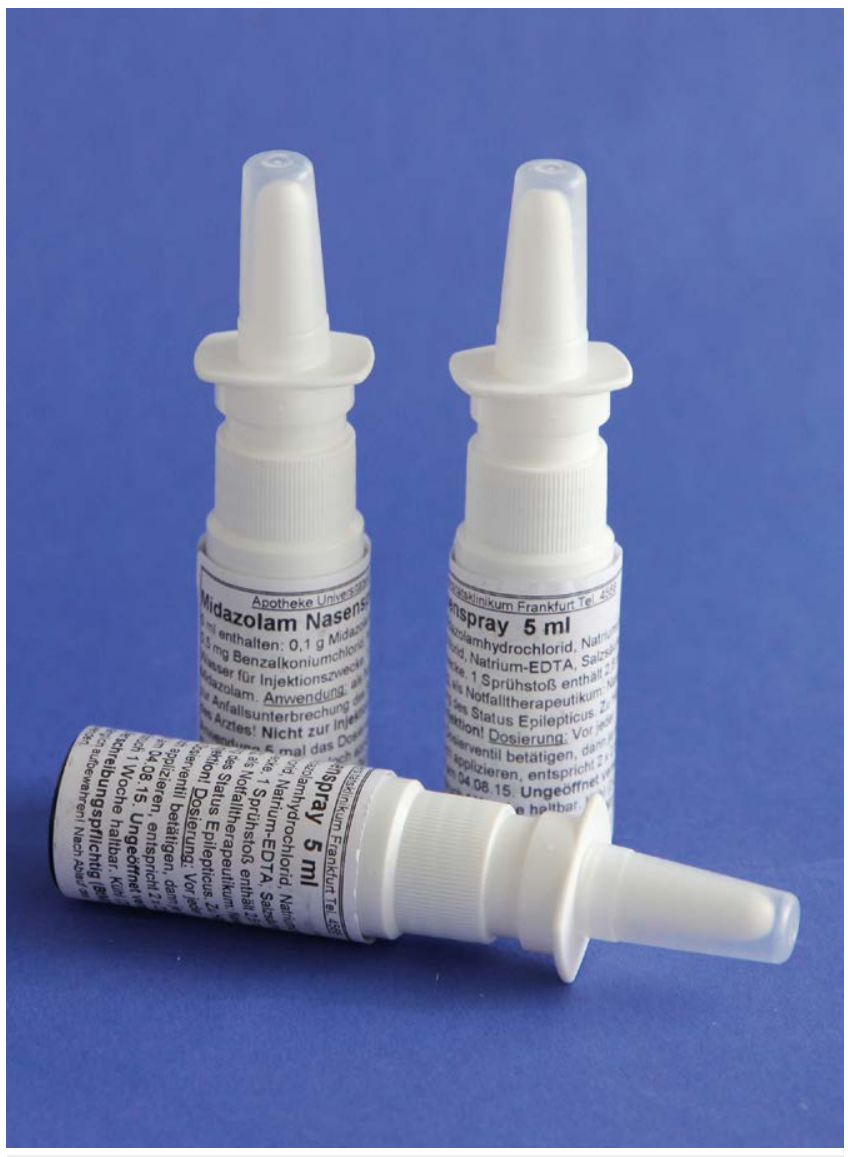

- Fig. 1 Ready-to-use midazolam nasal spray. The nasal spray delivers reproducible and standardized doses of $2.5 \mathrm{mg}$ midazolam in $140 \mu$ solution per puff. Rapid absorption via the nasal mucous membrane is ensured by the low puff volume.

costs are not covered by the statutory health insurances due to the off-label nature of its use in adults. No intranasal dosage form of midazolam has yet become commercially available; currently, such a medication is being evaluated in a clinical trial (NCT01390220).
- Table 2 Formulation of midazolam nasal spray, $5 \mathrm{ml}$ (adapted from $[38,63])$.

\begin{tabular}{|c|c|}
\hline Midazolam hydrochloride * & $99.25 \mathrm{mg}$ \\
\hline Sodium chloride & $32 \mathrm{mg}$ \\
\hline Benzalkonium chloride & $0.5 \mathrm{mg}$ \\
\hline Sodium EDTA & $5 \mathrm{mg}$ \\
\hline Purified water & to $5 \mathrm{ml}$ \\
\hline
\end{tabular}

* Midazolam hydrochloride $99.25 \mathrm{mg} \cong$ midazolam $89.3 \mathrm{mg} ; \mathrm{pH}$ of

3.3 achieved with $1 \mathrm{~N}$ hydrochloric acid

However, commercially available MDZ vials can be use do administer MDZ via the intranasal route: For this, the solution for injection is to be transferred to a syringe, followed by intranasal administration using an atomizer (mucosal atomization device). Here, it is important to pay attention to the various commercially available MDZ dilutions and vial sizes (MDZ $5 \mathrm{mg} / 5 \mathrm{ml}, 5 \mathrm{mg} / 1 \mathrm{ml}$ or $15 \mathrm{mg} / 3 \mathrm{ml}$ ). A more convenient method of administration is to use a concentrated MDZ nasal spray which has already been evaluated during video-EEG monitoring and established successfully [38]. It was shown that intranasal administration of MDZ significantly delayed seizure recurrence and reduced the likelihood of generalized tonic-clonic seizures [38]. This concentrated MDZ nasal spray ( $\triangleright$ Fig. 1) can be prepared by pharmacies; for details of the formulation refer to $\triangleright$ Table 2. One puff of the spray (volume of $140 \mu \mathrm{l}$ ) contains $2.5 \mathrm{mg}$ MDZ. To dissolve MDZ in an aqueous solution, an acidic $\mathrm{pH}$ of 3.3 is required. As a result, up to $5 \%$ of cases may experience irritation of the nasal mucosa [38]. The clear and colorless nasal spray can be stored at room temperature in a dark place for up to 3 months; the nasal spray must not be stored in a fridge as this could lead to the formation of precipitations in the solution.

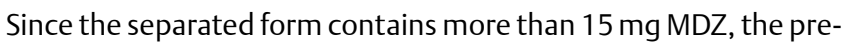
scription of the nasal spray falls under Appendix III of the German 
- Table 3 Summary of conventional anticonvulsants with intravenous application forms, listed by date of approval.

\begin{tabular}{|c|c|c|c|c|c|c|}
\hline & Phenobarbital & Phenytoin & Valproate & Levetiracetam & Lacosamide & Brivaracetam \\
\hline $\begin{array}{l}\text { Typical initial dose in } \\
\text { adults§ }\end{array}$ & $500-700 \mathrm{mg}$ & $\begin{array}{l}1200- \\
1500 \mathrm{mg}\end{array}$ & $2100 \mathrm{mg}$ & $2000-4000 \mathrm{mg}$ & $400 \mathrm{mg}$ & $200 \mathrm{mg}$ \\
\hline Intravenous dosage & $10 \mathrm{mg} / \mathrm{kg} \mathrm{BW \#}$ & $\begin{array}{l}15-20 \mathrm{mg} / \mathrm{kg} \\
\text { BW" }^{\#}\end{array}$ & $30 \mathrm{mg} / \mathrm{kg}$ BW & $\begin{array}{l}30-60 \mathrm{mg} / \mathrm{kg} \\
\text { BW }\end{array}$ & $\begin{array}{l}5 \mathrm{mg} / \mathrm{kg} \mathrm{BW} \\
200-600 \mathrm{mg}\end{array}$ & $100-400 \mathrm{mg}$ \\
\hline Infusion speed & $100 \mathrm{mg} / \mathrm{min}$ & $\begin{array}{l}\max .50 \mathrm{mg} / \\
\min , \max . \\
30 \mathrm{mg} / \mathrm{kg}\end{array}$ & $\begin{array}{l}\max .10 \mathrm{mg} / \mathrm{kg} / \\
\min \end{array}$ & $\begin{array}{l}\max .500 \mathrm{mg} / \\
\min \end{array}$ & $15 \mathrm{~min}$ & bolus injection \\
\hline Target serum concentration & $30-50 \mu \mathrm{g} / \mathrm{ml}$ & $20-25 \mu \mathrm{g} / \mathrm{ml}$ & $100-120 \mu \mathrm{g} / \mathrm{ml}$ & not known & not known & not known \\
\hline Half-life & $60-150 h$ & $20-60 h$ & $12-16 h$ & $6-8 h$ & $13 \mathrm{~h}$ & $8-9 h$ \\
\hline $\begin{array}{l}\text { Measuring serum } \\
\text { concentration }\end{array}$ & $\begin{array}{l}\text { recommended } \\
\text { (toxic from } \\
50 \mu \mathrm{g} / \mathrm{ml} \text { ) }\end{array}$ & $\begin{array}{l}\text { recommended } \\
\text { (toxic from } \\
25 \mu \mathrm{g} / \mathrm{ml} \text { ) }\end{array}$ & $\begin{array}{l}\text { no (adverse } \\
\text { effects from } \\
100 \mu \mathrm{g} / \mathrm{ml} \text { ) }\end{array}$ & no & no & no \\
\hline Interactions & many & many & many & none & none & minimal \\
\hline Respiratory depression & yes & no & no & no & no & no \\
\hline Circulatory depression & $\begin{array}{l}\text { monitoring } \\
\text { required * }\end{array}$ & $\begin{array}{l}\text { monitoring } \\
\text { required * }\end{array}$ & no & no & no* & no \\
\hline Vigilance & sedation & sedation & somnolence & somnolence & somnolence & somnolence \\
\hline Tissue toxicity & high & very high & $\begin{array}{l}\text { strict IV } \\
\text { administration }\end{array}$ & very low & very low & very low \\
\hline \multicolumn{7}{|l|}{ BW: body weight } \\
\hline \multicolumn{7}{|c|}{$\begin{array}{l}\text { * Acute high-dose intravenous phenytoin or phenobarbital should always be administered with ECG und blood pressure monitoring in an ICU setting. } \\
\text { ECG monitoring is recommended when lacosamide is administered-especially in combination with sodium channel blockers-as it can cause PR } \\
\text { interval prolongation }\end{array}$} \\
\hline
\end{tabular}

Narcotics Act (Betäubungsmittelgesetz, BtMG); thus, the nasal spray must be prescribed and documented for each patient individually.

For rectal administration, $5 \mathrm{mg}$ and $10 \mathrm{mg}$ of rectal DZP are available in $2.5 \mathrm{ml}$ rectal solution and approved for the treatment of SE. For decades, DZP has been used in prehospital treatment [39]. However, the rectal administration of medications, especially in the public, is not fully accepted by society and associated with negative psychosocial effects, such as embarrassment and stigmatization $[40,41]$. Currently, a trend towards buccal or intranasal administration of benzodiazepine is noted $[42,43]$.

\section{Treatment with Intravenous Anticonvulsants (Stage 2)}

Rapid loading with anticonvulsants is required in patients with persisting SE or after termination of SE with benzodiazepines to prevent seizure recurrence. Intravenous dosage forms, listed according to the approval dates of the various anticonvulsants, are available for phenobarbital (PB), phenytoin (PHT), valproic acid (VPA), levetiracetam (LEV), lacosamide (LCM), and brivaracetam (BRV); refer to > Table 3. The DGN Guideline on the Management of SE in Adults recommends the use of $\mathrm{PHT}$; as alternative medications or in case PHT is contraindicated, VPA, LEV and PB are taken into consideration [6].

PHT should be administered at a dose of $20 \mathrm{mg} / \mathrm{kg}$ body weight (BW) (max. $50 \mathrm{mg} / \mathrm{min}$, max. $30 \mathrm{mg} / \mathrm{kg}$ BW) via a secure large-bore IV access, ideally a central venous catheter [44]. PHT is available both as an infusion concentrate $(750 \mathrm{mg} / 50 \mathrm{ml})$ and as an injection solution $(250 \mathrm{mg} / 5 \mathrm{ml})$ with distinct PHT doses. The highly alkaline PHT solution must not be diluted with other substances as this could result in the precipitation of free phenytoin base. For the further treatment, it should be attempted to achieve a target phenytoin level of $20 \mu \mathrm{g} / \mathrm{ml}$ (up to max. $25 \mu \mathrm{g} / \mathrm{ml}$ ). The comparably slow infusion speed should not be exceeded in the light of PHT's proarrhythmogenic effect-a disadvantage of this medication. According to its summary of product characteristics, PHT is contraindicated in patients with second- or third-degree atrioventricular block, myocardial infarction during the last 3 months and heart failure with an ejection fraction under $35 \%$. In addition, similar to thiopental, phenytoin exhibits local tissue toxicity; thus, intravenous access should be large-bore and secure to avoid tissue necrosis associated with extravasation. Irreversible damage of the cerebellum may result from phenytoin intoxication [45]. These toxicities limit the use of phenytoin as a first-line treatment in patients who have no indwelling central venous catheter or where continuous monitoring of vital signs is not available; thus at our hospitals, PHT is 
used as drug of 4th choice after LEV, VPA and LCM [3], and other centers pursue similar management strategies [46-48]. Furthermore, this approach reflects the current prescribing behavior in patients with epilepsy in Germany: in over $50 \%$ of patients, treatment is started with LEV at first diagnosis $[49,50]$.

VPA should be infused at a dose of $20-30 \mathrm{mg} / \mathrm{kg}$ BW, max. $10 \mathrm{mg} / \mathrm{kg} / \mathrm{min}$, to be repeated after $10 \mathrm{~min}$, if necessary, then at a dose of max. $10 \mathrm{mg} / \mathrm{kg}$. For the further treatment, it should be attempted to achieve a target VPA level of $100-120 \mu \mathrm{g} / \mathrm{ml}$. VPA is available at a concentration of $100 \mathrm{mg} / \mathrm{ml}$ in various dose sizes, with $300 \mathrm{mg}, 400 \mathrm{mg}$ and $1000 \mathrm{mg}$ per vial. A major contraindication is known mitochondriopathy. According to the summary of product characteristics, VPA is also contraindicated in patients with insulin-dependent diabetes mellitus or porphyria. Since VPA can cause a platelet dysfunction (thrombocytopathy), its use in patients with increased susceptibility to bleeding and in need of surgical treatment is problematic. Further contraindications include hepatic disorder, pancreatitis and oral anticoagulation with vitamin K antagonists such as warfarin or phenprocoumon (susceptibility to bleeding and INR imbalance). Furthermore, it is often difficult to achieve adequate serum levels in patients with carbapenem antibiotics as co-medication [51].

LEV is to be administered at a dose of $30 \mathrm{mg} / \mathrm{kg}$ BW with the maximum infusion speed of $500 \mathrm{mg} / \mathrm{min}$; if required, this can be repeated after $10 \mathrm{~min}$ (maximum total dose of $60 \mathrm{mg} / \mathrm{kg} \mathrm{BW}$ ). The target level for LEV treatment has not yet been established. In patients with renal impairment, dose adjustment is required for continuing therapy.

PB can be administered at doses of up to $20 \mathrm{mg} / \mathrm{kg}$ BW (max. $100 \mathrm{mg} / \mathrm{min}$ ) [44]. Higher total doses require intensive care monitoring as well as preparedness for intubation and mechanical ventilation; consequently, as with PHT, its use is contraindicated where adequate monitoring cannot be ensured. In addition, drug-drug interaction as well as intoxication risks have to be taken into consideration when PB is used in combination with VPA. In patients with hepatic impairment, PB should not be used. For the further treatment, it should be attempted to achieve a target PB level of $30-50 \mu \mathrm{g} / \mathrm{ml}$.

Since 2008 LCM has been available as an intravenous anticonvulsant. According to a recent systematic review, it has been used in more than 500 cases to treat SE; its efficacy was $57 \%$ and its tolerability profile was favorable [52]. Usually, a dose of $5 \mathrm{mg} / \mathrm{kg} \mathrm{BW}$ is administered over $\geq 15 \mathrm{~min}$ (initial dose of 200 to $400 \mathrm{mg}$ ) [5355]. As with LEV, LCM has not yet been approved for the treatment of SE. Since PR interval prolongation have been observed with LCM, it should be used with caution in patients with known second-degree or higher AV block and in patients with cardiac disease. Dose adjustment is required in patients with renal or hepatic impairment.

Approved in 2016, BRV is the latest intravenous anticonvulsant that has become available and data on its use to treat SE are limited to just a few cases [56]. Most commonly, starting dosages of 200 to $400 \mathrm{mg}$ are used; in contrast to other intravenous anticonvulsants, undiluted solution can be used for bolus injection, further cutting down the time to treatment in SE. BRV has not yet been ap-
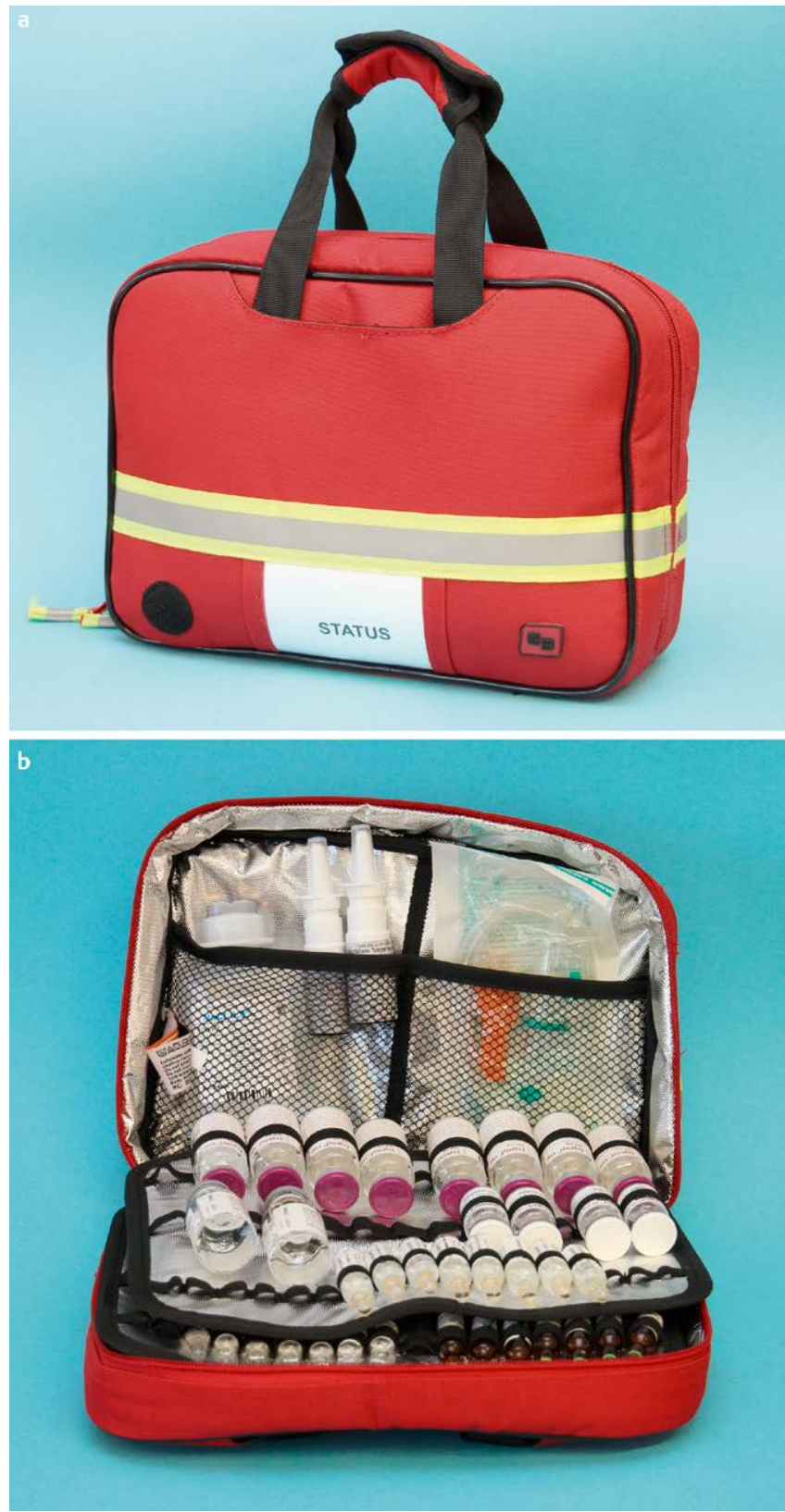

- Fig. 2 The SE emergency kit used in Frankfurt for the initial treatment of status epilepticus in settings with limited monitoring capabilities.

proved for treatment of SE. All in all, BRV is a well-tolerated antiepileptic drug (AED) with a lower incidence of psychobehavioral adverse events compared with LEV $[57,58]$. Switching from LEV to BRV is possible and a ratio between 15:1 and 10:1 can be applied [57]. Dose adjustment is required in patients with hepatic or renal impairment $[59,60]$. Since BRV crosses the blood-brain barrier significantly faster than LEV and attains its maximum concentration in the brain within minutes after intravenous administration [61], future studies will have to clarify whether BRV treatment starting with a bolus injection for rapid loading offers advantages in the emergency situation. 


\section{Concepts for Management Outside Intensive Care Units}

Neither in the prehospital nor in the in-hospital setting should the treatment of SE be unnecessarily delayed. An established local treatment pathway should be in place to ensure that treatment is started immediately after diagnosis, already outside the emergency department or intensive care unit. In patients in whom SE is suspected based on EEG findings, the technician should inform the treating physician experienced in EEG interpretation so that, once the diagnosis of SE is confirmed, treatment can be started. If SE is diagnosed in the clinical neurophysiology department, it has proven to be beneficial to bring along an SE emergency kit ( $\vee$ Fig. 2) so treatment can be started while an EEG is recorded. Midazolam can be administered intranasally if intravenous access is not yet established; once established, conventional anticonvulsants such as LEV, VPA, LCM or BRV should be administered intravenously-the monitoring capabilities of an emergency department or intensive care unit are not required for this step. Further treatment is then provided in an intensive care unit.

\section{Conclusion}

In conclusion, besides uncontrollable factors such as etiology, comorbidity and age of patient, rapid initiation of treatment with benzodiazepines and other anticonvulsants in high enough doses is critical for a successful therapy. In prehospital and in-hospital settings outside of intensive care units where monitoring capabilities are limited, the treatment of SE has to be adapted to local conditions. Therapy should be continued in a neurocritical care unit, especially when treatment with PHT or PB or stage 3 or 4 therapy is required. To ensure initial treatment is started without delay, it is critical to establish a local treatment pathway [62] so that the recommended treatment can be provided immediately.

\section{Conflict of interest}

L. Kay, A. von Blomberg and L.M. Willems declare that no conflict of interest exists. A. Strzelczyk received consulting and lecture fees and/or support for research projects from Bayer HealthCare, Boehringer Ingelheim, Desitin Arzneimittel, Eisai, LivaNova, Pfizer, Sage Therapeutics, UCB Pharma, and Zogenix. C. Kellinghaus received consulting and lecture fees from Cerbomed, Desitin, Eisai, and UCB Pharma. S. Knake received consulting and lecture fees from Desitin and UCB Pharma. F. Rosenow received consulting fees from GlaxoSmithKline, Eisai, UCB Pharma, Shire, Sandoz, and Pfizer. He received lecture fees from UCB Pharma, GlaxoSmithKline, Eisai, Hexal, Desitin, and Medtronic as well as support for continuing medical education (CME) events from Nihon-Kohden, UCB Pharma, Medtronics, Cyberonics, and Cerbomed.
References

[1] Betjemann JP, Lowenstein DH. Status epilepticus in adults. Lancet Neurol 2015; 14: 615-624

[2] Knake S, Rosenow F, Vescovi M et al. Incidence of status epilepticus in adults in Germany: A prospective, population-based study. Epilepsia 2001; 42: 714-718

[3] Kortland LM, Alfter A, Bähr O et al. Costs and cost-driving factors for acute treatment of adults with status epilepticus: A multicenter cohort study from Germany. Epilepsia 2016; 57: 2056-2066

[4] Strzelczyk A, Knake S, Oertel WH et al. Inpatient treatment costs of status epilepticus in adults in Germany. Seizure 2013; 22: 882-885

[5] Trinka E, Cock H, Hesdorffer D et al. A definition and classification of status epilepticus - Report of the ILAE Task Force on Classification of Status Epilepticus. Epilepsia 2015; 56: 1515-1523

[6] Rosenow F. Status epilepticus im Erwachsenenalter. In: Diener HC, Weimar C, (Hrsg.). Leitlinien für Diagnostik und Therapie in der Neurologie. Stuttgart: Thieme Verlag; 2012

[7] Lowenstein DH, Bleck T, Macdonald RL. It's time to revise the definition of status epilepticus. Epilepsia 1999; 40: 120-122

[8] Lowenstein DH, Alldredge BK. Status epilepticus at an urban public hospital in the 1980s. Neurology 1993; 43: 483-488

[9] Kapur ], Macdonald RL. Rapid seizure-induced reduction of benzodiazepine and Zn2 + sensitivity of hippocampal dentate granule cell GABAA receptors. J Neurosci 1997; 17: 7532-7540

[10] Alldredge BK, Gelb AM, Isaacs SM et al. A comparison of lorazepam, diazepam, and placebo for the treatment of out-of-hospital status epilepticus. N Engl J Med 2001; 345: 631-637

[11] Shorvon S, Ferlisi M. The treatment of super-refractory status epilepticus: A critical review of available therapies and a clinical treatment protocol. Brain 2011; 134: 2802-2818

[12] Holtkamp M, Othman J, Buchheim K et al. A "malignant" variant of status epilepticus. Arch Neurol 2005; 62: 1428-1431

[13] Strzelczyk A, Kortland LM, Knake $S$ et al. Stiripentol for the treatment of super-refractory status epilepticus. Acta Neurol Scand 2015; 132: 435-439

[14] Thakur KT, Probasco JC, Hocker SE et al. Ketogenic diet for adults in super-refractory status epilepticus. Neurology 2014; 82: 665-670

[15] Rohracher A, Höfler J, Kalss G et al. Perampanel in patients with refractory and super-refractory status epilepticus in a neurological intensive care unit. Epilepsy Behav 2015; 49: 354-358

[16] Broomall E, Natale JE, Grimason M et al. Pediatric super-refractory status epilepticus treated with allopregnanolone. Ann Neurol 2014; 76: 911-915

[17] Levesque M, Herrington R, Leclerc L et al. Allopregnanolone decreases interictal spiking and fast ripples in an animal model of mesial temporal lobe epilepsy. Neuropharmacology 2017; 121: 12-19

[18] Chen JW, Wasterlain CG. Status epilepticus: Pathophysiology and management in adults. Lancet Neurol 2006; 5: 246-256

[19] Prasad M, Krishnan PR, Sequeira R et al. Anticonvulsant therapy for status epilepticus. Cochrane database of systematic reviews 2014, doi:10.1002/14651858.CD003723.pub3: CD003723

[20] Crevoisier C, Delisle MC, Joseph I et al. Comparative single-dose pharmacokinetics of clonazepam following intravenous, intramuscular and oral administration to healthy volunteers. Eur Neurol 2003; 49: 173-177

[21] Alvarez V, Lee JW, Drislane FW et al. Practice variability and efficacy of clonazepam, lorazepam, and midazolam in status epilepticus: A multicenter comparison. Epilepsia 2015; 56: 1275-1285 
[22] Silbergleit R, Lowenstein D, Durkalski V et al. RAMPART (Rapid Anticonvulsant Medication Prior to Arrival Trial): A double-blind randomized clinical trial of the efficacy of intramuscular midazolam versus intravenous lorazepam in the prehospital treatment of status epilepticus by paramedics. Epilepsia 2011; 52: (Suppl 8): 45-47

[23] Silbergleit R, Durkalski V, Lowenstein D et al. Intramuscular versus intravenous therapy for prehospital status epilepticus. N Engl J Med 2012; 366: 591-600

[24] Welch RD, Nicholas K, Durkalski-Mauldin VL et al. Intramuscular midazolam versus intravenous lorazepam for the prehospital treatment of status epilepticus in the pediatric population. Epilepsia 2015; 56: 254-262

[25] Silbergleit R, Lowenstein D, Durkalski V et al. Lessons from the RAMPART study-and which is the best route of administration of benzodiazepines in status epilepticus. Epilepsia 2013; 54 (Suppl 6): 74-77

[26] Crawford TO, Mitchell WG, Snodgrass SR. Lorazepam in childhood status epilepticus and serial seizures: Effectiveness and tachyphylaxis. Neurology 1987; 37: 190-195

[27] Scott RC, Besag FM, Neville BG. Buccal midazolam and rectal diazepam for treatment of prolonged seizures in childhood and adolescence: $A$ randomised trial. Lancet 1999; 353: 623-626

[28] Lahat E, Goldman M, Barr J et al. Comparison of intranasal midazolam with intravenous diazepam for treating febrile seizures in children: Prospective randomised study. BMJ 2000; 321: 83-86

[29] Fisgin T, Gurer Y, Tezic T et al. Effects of intranasal midazolam and rectal diazepam on acute convulsions in children: Prospective randomized study. J Child Neurol 2002; 17: 123-126

[30] Mahmoudian T, Zadeh MM. Comparison of intranasal midazolam with intravenous diazepam for treating acute seizures in children. Epilepsy Behav 2004; 5: 253-255

[31] Mclntyre J, Robertson S, Norris E et al. Safety and efficacy of buccal midazolam versus rectal diazepam for emergency treatment of seizures in children: A randomised controlled trial. Lancet 2005; 366 : 205-210

[32] Ashrafi MR, Khosroshahi N, Karimi P et al. Efficacy and usability of buccal midazolam in controlling acute prolonged convulsive seizures in children. Eur J Paediatr Neurol 2010; 14: 434-438

[33] de Haan G], van der Geest P, Doelman G et al. A comparison of midazolam nasal spray and diazepam rectal solution for the residential treatment of seizure exacerbations. Epilepsia 2010; 51: 478-482

[34] Holsti M, Dudley N, Schunk J et al. Intranasal midazolam vs rectal diazepam for the home treatment of acute seizures in pediatric patients with epilepsy. Arch Pediatr Adolesc Med 2010; 164: 747-753

[35] Arya R, Gulati S, Kabra M et al. Intranasal versus intravenous lorazepam for control of acute seizures in children: A randomized open-label study. Epilepsia 2011; 52: 788-793

[36] McMullan J, Sasson C, Pancioli A et al. Midazolam versus diazepam for the treatment of status epilepticus in children and young adults: A meta-analysis. Acad Emerg Med 2010; 17: 575-582

[37] Thakker A, Shanbag P. A randomized controlled trial of intranasal-midazolam versus intravenous-diazepam for acute childhood seizures. J Neurol 2013; 260: 470-474

[38] Kay L, Reif PS, Belke M et al. Intranasal midazolam during presurgical epilepsy monitoring is well tolerated, delays seizure recurrence, and protects from generalized tonic-clonic seizures. Epilepsia 2015; 56: $1408-1414$

[39] Kriel RL, Cloyd JC, Hadsall RS et al. Home use of rectal diazepam for cluster and prolonged seizures: Efficacy, adverse reactions, quality of life, and cost analysis. Ped Neurol 1991; 7: 13-17

[40] Timmerman A, Jennekens-Schinkel A, Oostrom KJ et al. Stesolid emergency treatment: Cave social fear!. Seizure 2008; 17: 333-338

[41] Tatum IW. Adult patient perceptions of emergency rectal medications for refractory seizures. Epilepsy Behav 2002; 3: 535-538
[42] Brigo F, Nardone R, Tezzon F et al. A common reference-based indirect comparison meta-analysis of buccal versus intranasal midazolam for early status epilepticus. CNS Drugs 2015; 29: 741-757

[43] Trinka E, Brigo F, Shorvon S. Recent advances in status epilepticus. Curr Op Neurology 2016; 29: 189-198

[44] Treiman DM, Meyers PD, Walton NY et al. A comparison of four treatments for generalized convulsive status epilepticus. Veterans Affairs Status Epilepticus Cooperative Study Group. N Engl J Med 1998; 339: 792-798

[45] Kuruvilla T, Bharucha NE. Cerebellar atrophy after acute phenytoin intoxication. Epilepsia 1997; 38: 500-502

[46] Rohracher A, Reiter DP, Brigo F et al. Status epilepticus in the elderly-A retrospective study on 120 patients. Epilepsy Res 2016; 127: 317-323

[47] Sutter R, Marsch S, Fuhr $P$ et al. Anesthetic drugs in status epilepticus: Risk or rescue? A 6-year cohort study. Neurology 2014; 82: 656-664

[48] Kellinghaus C, Stogbauer F. Treatment of status epilepticus in a large community hospital. Epilepsy Behav 2012; 23: 235-240

[49] Ertl J, Hapfelmeier J, Peckmann T et al. Guideline conform initial monotherapy increases in patients with focal epilepsy: A population-based study on German health insurance data. Seizure 2016; 41: 9-15

[50] Strzelczyk A, Bergmann A, Biermann V et al. Neurologist adherence to clinical practice guidelines and costs in patients with newly diagnosed and chronic epilepsy in Germany. Epilepsy Behav 2016; 64: 75-82

[51] Bede P, Lawlor D, Solanki D et al. Carbapenems and valproate: A consumptive relationship. Epilepsia Open 2017; 2: 107-111

[52] Strzelczyk A, Zöllner JP, Willems LM et al. Lacosamide in status epilepticus: Systematic review of current evidence. Epilepsia 2017; 58: 933-950

[53] Höfler ], Unterberger I, Dobesberger J et al. Intravenous lacosamide in status epilepticus and seizure clusters. Epilepsia 2011; 52: e148-e152

[54] Kellinghaus C, Berning S, Immisch I et al. Intravenous lacosamide for treatment of status epilepticus. Acta Neurol Scand 2011; 123 : 137-141

[55] Lang N, Lange M, Schmitt FC et al. Intravenous lacosamide in clinical practice-Results from an independent registry. Seizure 2016; 39: 5-9

[56] Strzelczyk A, Steinig I, Willems LM et al. Treatment of refractory and super-refractory status epilepticus with brivaracetam: A cohort study from two German university hospitals. Epilepsy Behav 2017; 70(pt A): $177-181$

[57] Steinig I, von Podewils F, Möddel G et al. Postmarketing experience with brivaracetam in the treatment of epilepsies: A multicentre cohort study from Germany. Epilepsia 2017; 58: 1208-1216

[58] Yates SL, Fakhoury T, Liang W et al. An open-label, prospective, exploratory study of patients with epilepsy switching from levetiracetam to brivaracetam. Epilepsy Behav 2015; 52: 165-168

[59] Brandt C, May TW, Bien CG. Brivaracetam as adjunctive therapy for the treatment of partial-onset seizures in patients with epilepsy: The current evidence base. Ther Adv Neurol Dis 2016; 9: 474-482

[60] Strzelczyk A, Klein KM, Willems LM et al. Brivaracetam in the treatment of focal and idiopathic generalized epilepsies and of status epilepticus. Expert Rev Clinical Pharmacol 2016; 9: 637-645

[61] Nicolas JM, Hannestad J, Holden D et al. Brivaracetam, a selective high-affinity synaptic vesicle protein 2A (SV2A) ligand with preclinical evidence of high brain permeability and fast onset of action. Epilepsia 2016; 57: 201-209

[62] Jones S, Pahl C, Trinka E et al. A protocol for the inhospital emergency drug management of convulsive status epilepticus in adults. Pract Neurol 2014; 14: 194-197

[63] Neues Rezeptur-Formularium. Midazolam-Rezepturen. ABDA - Bundesvereinigung Deutscher Apothekerverbände 2002 